\title{
Artificial Intelligence Diagnosa Kerusakan Mobil dengan Algoritma Dempster Shafer Berbasis Codeigneter
}

\author{
Mokhammad Rifqi Tsani \\ email: rifqi@pktj.ac.id \\ Politeknik Keselamatan Transportasi Jalan
}

\begin{abstract}
Abstrak
Dalam ilmu komputer, banyak ahli yang berkonsentrasi pada pengembangan kecerdasan buatan atau Artificial Intelligence (AI). AI adalah suatu studi khusus di mana tujuannya adalah membuat komputer berfikir dan bertindak seperti manusia. Banyak implementasi AI dalam bidang komputer, misalnya Decision Support System (Sistem Penunjang Keputusan), Robotic, Natural Language (Bahasa Alami), Neural Network (Jaringan Saraf), dan lain-lain.Sistem pakar adalah salah satu dari Artificial Intelligence (AI) yang sangat menarik untuk dikembangkan, seperti di bidang otomotif tentang mendeteksi dan penanganan kerusakan pada Mobil membutuhkan konsultasi perbaikan dengan cepat dan akurat. Oleh karena permasalahan tersebut, maka diperlukan suatu sistem yang dapat mengatasi persoalan diatas. Dimana nantinya hasil dari diagnose Artificial Intelligence (AI) ini akan dapat sangat membantu pemilik Mobil. Dengan menggunakan Algoritma dempster shafer pada sistem AI tersebut diharapkan lebih efektif dan akurat untuk hasilnya. Pada penelitian ini menggunakan metode penelitian SDLC (Software Development Life Cycle) waterfall. Untuk pembuatan Aplikasinya menggunakan bahasa pemrograman Codeigniter dengan database MySQL. Aplikasi ini dapat membantu pengguna mobil/sopir untuk mengetahui gejala kerusakan lebih awal pada mobil serta dapat digunakan sebagai media pembelajaran taruna PKTJ Tegal pada bidang otomotif.
\end{abstract}

Kata kunci : artificial intelligence, mobil, Dempster Shafer, codeigniter.

\section{Pendahuluan}

Mobil merupakan kendaraan atau kereta tanpa berkuda yang dapat berjalan sendiri. Kemudian dikembangkan pada tahun 1885 oleh orang Jerman yang bernama Kart Benz yang menciptakan mobil Benz yang dapat mengangkut penumpang dan merupakan mobil bensin periode awal. Saat ini mobil banyak beredar dengan banyak merek dan tipe. Mekanik adalah teknisi yang mempunyai tanggung jawab yang besar terhadap mobil yang dibawa oleh pemilik kendaraan untuk diservice, namun karena banyaknya mobil dengan tipe yang berbeda membuat mekanik terkadang bingung dan lupa akan mekanisme kerja mobil tertentu, sehingga harus membuka buku-buku untuk mengetahui kerusakan mobil yang ditanganinya. Untuk menanggulangi hal tersebut, dibutuhkan suatu alat bantu untuk mengendentifikasi kerusakan yang terjadi pada mobil (Setright, 2004).

Pada era Industri 4.0 dikembangkan pula teknologi yang mampu mengadopsi proses dan cara berpikir manusia yaitu teknologi Artificial Intelligence atau Kecerdasan Buatan. Sistem Pakar adalah salah satu cabang Artificial Intelligence yang membuat penggunaan secara luas knowledge yang khusus untuk penyelesaian masalah tingkat manusia yang pakar ke dalam suatu area pengetahuan tertentu sehingga setiap orang dapat menggunakannya untuk memecahkan berbagai masalah yang bersifat spesifik dalam hal ini adalah permasalahan pada kinerja mesin Mobil. Menurut Sri Kusuma Dewi (2003:1), Kecerdasan buatan atau artificial inteligence merupakan salah satu bagian ilmu komputer yang membuat agar mesin (komputer) dapat melakukan pekerjaan seperti dan sebaik yang dilakukan oleh manusia.

Kerusakan pada mesin mobil terjadi akibat kelalaian dalam melakukan perawatan. Pemilik mobil baru menyadari kerusakan setelah mobil tidak dapat beroperasi sebagaimana mestinya. Oleh karena itu dalam penggunaan mobil kemungkinan besar membutuhkan perawatan berkala. Dengan cara mendeteksi kerusakan apa yang terjadi pada mobil. Misalnya, bila kopling sulit bebas dan tidak mempunyai gambaran mengapa hal tersebut terjadi, hal inilah yang mendorong pembangunan artificial inteligence (AI) untuk mengidentifikasi kerusakan mesin mobil dengan menggunakan metode Dempster Shafer berbasis codeigniter. Pada penelitian Haryono Yusman dkk (2017) untuk diagnosa kerusakan pada mobil toyota menggunakan 
metode CF (Certainty Factor) dengan implementasi menggunakan bahasa pemrograman android. Pada penelitian Siswan Syahputra dkk (2018) dilakukan menggunakan metode Backward Chaining untuk dignosa kerusakan pada mobil. Dalam penelitian Rikhiana dkk (2017) Dempster Shafer digunakan untuk mendiagnosa penyakit dalam pada manusia.

\section{Metode Penelitian}

Penelitian ini bertujuan untuk membuat sebuah sistem informasi artificiall intelegence untuk diagnosa kerusakan mobil yang efektif dan efisien . Pada gambar 1 menggambarkan model desain penelitian menggunakan SDLC (System Development life Cycle), dengan metode Waterfall. Waterfall adalah pendekatan SDLC paling awal yang digunakan untuk pengembangan perangkat lunak. Hal ini juga disebut sebagai model SDLC linear-sekuensial. Hal ini sangat sederhana untuk memahami dan menggunakanya dalam mengimplementasikan sebuah sistem.

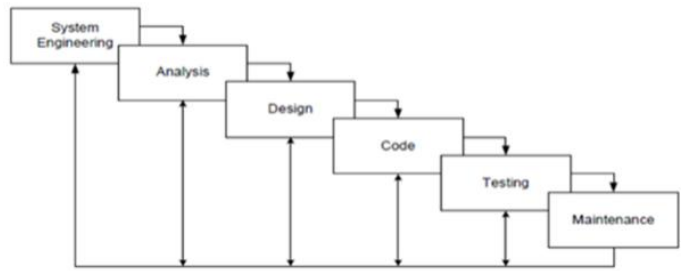

Gambar 1. Desain Penelitian (Waterfall Model)

(Sumber: Pressman, 2012:39)

\section{a) Perancangan Sistem (Sistem Engineering)}

Perancangan sistem diperlukan untuk bagian dari suatu sistem yang lebih besar nantinya Pembuatan sebuah piranti lunak dapat dimulai dengan melihat dan mencari apa yang dibutuhkan oleh sistem. Dari kebutuhan sistem tersebut akan diterapkan kedalam piranti lunak yang dibuat.

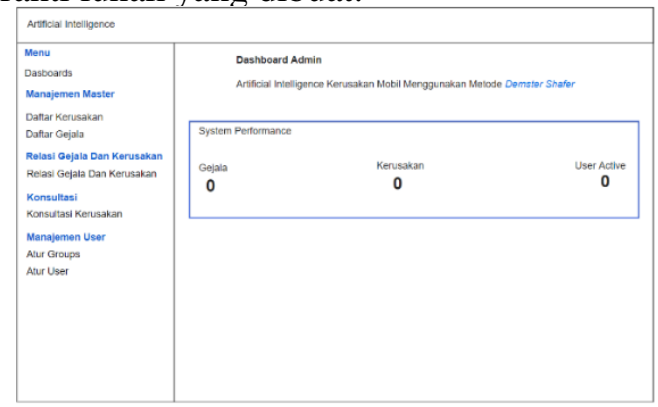

Gambar 2. Perancangan Aplikasi AI

\section{b) Analisa Kebutuhan Piranti Lunak (Software Requirement Analysis)}

Merupakan proses pengumpulan kebutuhan piranti lunak. Untuk memahami dasar dari program yang akan dibuat, seorang analisis harus mengetahui ruang lingkup informasi, fungsi-fungsi yang dibutuhkan, kemampuan kinerja yang ingin dihasilkan dan perancangan antarmuka pemakai piranti lunak tersebut. Pada tahap ini akan membahas kebutuhan perangkat keras, perangkat lunak dan data untuk dignosa kerusakan mobil.

c) Perancangan (Design)

Perancangan piranti lunak menggunakan UML (Unified Modeling Language). Unified Modeling Language (UML) adalah sebuah bahasa pemodelan visual yang dirancang khusus untuk pengembangan dan analisis sistem berorientasi objek dan desain (Keng Siau and Qing Cao, 2001).

\section{d) Pengkodean (Coding)}

Pengkodean piranti lunak merupakan proses penulisan kedalam Bahasa pemograman agar piranti lunak tersebut dapat digunakan oleh mesin. Pada tahap ini akan menggunakan bahasa pemrograman Codeigniter dan Database MySql. Menurut Betha Sidik (2012) CodeIgniter adalah Sebuah framework php yang bersifat open source dan menggunakan metode MVC (Model, View, Controller).

\section{e) Pengujian (Testing)}

Proses ini akan menguji kode program yang telah dibuat dengan memfokuskan pada bagian dalam piranti lunak. Tujuannya untuk memastikan bahwa semua pernyataan telah diuji dan memastikan juga bahwa input yang digunakan akan menghasilkan output yang sesuai. Pada tahap ini pengujian menggunakan metode Black Box Testing.

\section{f) Pemeliharaan (Maintenance)}

Proses ini dilakukan setelah piranti lunak telah digunakan oleh user. Suatu Perubahan akan dilakukan jika terdapat kesalahan dan penyesuaian akan perubahan kebutuhan yang diinginkan user. 


\section{Hasil dan Pembahasan}

Pada langkah ini berisi pengumpulan kebutuhan secara lengkap untuk memenuhi dalam menganalisis dan mengidentifikasi kebutuhan apa saja yang diperlukan dalam pembuatan sebuah program artificial intelligence.

\section{A. Perangkat Lunak}

Perangkat lunak yang digunakan sebagai berikut:

\section{- Sistem Operasi}

Sistem operasi yang digunakan peneliti adalah Windows 10 Ultimate.

\section{- Notepad ++}

Notepad ++ digunakan sebagai editor dalam pembangunan program berbasis web.

\section{- Xampp}

Xampp digunakan untuk membuat database program dengan bahasa MySql.

\section{B. Perangkat Keras}

Berikut perangkat keras yang digunakan dalam membuat program artificial intelligence diagnosa kerusakan mobil, yaitu:

- Spesifikasi Personal Computer (PC) yang penulis gunakan sebagai berikut :

Processor : Intel ${ }^{\circledR}$ Core TM i7

Sistem Operasi : Windows 10

Ultimate RAM : 6 GB System

Type : 64 bit

- Modem Internet

- Mouse dan Keyboard

\section{Data Daftar Kerusakan dan Gejala Mobil}

Tabel 1. Daftar Kerusakan Mobil

\begin{tabular}{|c|c|c|c|}
\hline No & $\begin{array}{c}\text { Kode } \\
\text { Kerusakan }\end{array}$ & $\begin{array}{c}\text { Nama } \\
\text { Kerusakan }\end{array}$ & Solusi \\
\hline 1 & K001 & Busi & $\begin{array}{l}\text { Melakukan } \\
\text { pergantian busi } \\
\text { sesuai buku } \\
\text { panduan perbaikan } \\
\text { dan penggunaan } \\
\text { bahan bakar bebas } \\
\text { timbal } \\
\text { PERTAMAX) }\end{array}$ \\
\hline 2 & K002 & $\begin{array}{l}\text { Pompa } \\
\text { Bahan Bakar }\end{array}$ & $\begin{array}{l}\text { Melakukan } \\
\text { pergantian pompa } \\
\text { bahan bakar dan } \\
\text { mempertahankan } \\
\text { volume bahan bakar } \\
\text { didala tangki untuk } \\
\text { pendingin pompa } \\
\text { agar pompa tidak } \\
\text { cepat rusak. }\end{array}$ \\
\hline 3 & K003 & $\begin{array}{l}\text { Radiator } \\
\text { Bocor }\end{array}$ & \begin{tabular}{lr}
\multicolumn{2}{l}{ Mengganti radiator } \\
dan menggunakan \\
cairan pendingin \\
(freon) & yang \\
khusus. &
\end{tabular} \\
\hline
\end{tabular}

\begin{tabular}{|l|l|l|l|}
\hline 4 & K004 & $\begin{array}{l}\text { Ring Piston } \\
\text { Longgar }\end{array}$ & $\begin{array}{l}\text { Melakukan } \\
\text { pembongkaran dan } \\
\text { mesin ring } \\
\text { melakukan } \\
\text { pergantian } \\
\text { piston dan piston. }\end{array}$ \\
\hline 5 & K005 & $\begin{array}{l}\text { Knalpot } \\
\text { Tersumbat }\end{array}$ & $\begin{array}{l}\text { Melakukan } \\
\text { pembersihan } \\
\text { knalpot secara } \\
\text { berkala. }\end{array}$ \\
\hline
\end{tabular}

Tabel 2. Daftar Gejala Mobil

\begin{tabular}{|c|c|c|}
\hline No & $\begin{array}{c}\text { Kode } \\
\text { Gejala }\end{array}$ & Nama Gejala \\
\hline 1 & G001 & Bahan Bakar Boros \\
\hline 2 & G002 & Mesin Tersendat sendat \\
\hline 3 & G003 & IDLING mesin buruk \\
\hline 4 & G004 & Akselerasi Buruk \\
\hline 5 & G005 & Mesin Susah Hidup \\
\hline 6 & G006 & Mesin Mogok \\
\hline 7 & G007 & Mesin Tersendat sendat \\
\hline 8 & G008 & Tarikan Mesin Lemah \\
\hline 9 & G009 & Mesin Susah Hidup \\
\hline 10 & G010 & Temperatur Mesin Tidak Normal \\
\hline 11 & G011 & $\begin{array}{llll}\text { Uap Air Menyembur Keluar } & \mathrm{Ke} \\
\text { Radiator } & & & \\
\end{array}$ \\
\hline 12 & G012 & Oli Bercampur dengan Air \\
\hline 13 & G013 & Suara Mesin Knocking \\
\hline 14 & G014 & Mesin Tersendat Sendat \\
\hline 15 & G015 & Oli Mesin Berkurang \\
\hline 16 & G016 & Mesin Mengeluarkan Asap \\
\hline 17 & G017 & Lampu Indikator Oli Hidup Terus \\
\hline 18 & G018 & Mesin Tidak Dapat Berputar \\
\hline 19 & G019 & Suara Mesin Kasar \\
\hline 20 & G020 & Tarikan Mesin Lemah \\
\hline
\end{tabular}

Tabel 3. Relasi Gejala dan Kerusakan

\begin{tabular}{|c|c|c|c|c|}
\hline No & $\begin{array}{c}\text { Kode } \\
\text { Gejala }\end{array}$ & Nama Gejala & $\begin{array}{c}\text { Nama } \\
\text { Kerusakan }\end{array}$ & $\mathbf{C F}$ \\
\hline 1 & G001 & $\begin{array}{l}\text { Bahan Bakar } \\
\text { Boros }\end{array}$ & K001 - Busi & 0.50 \\
\hline 2 & G002 & $\begin{array}{l}\text { Mesin } \\
\text { Tersendat } \\
\text { sendat }\end{array}$ & K001 - Busi & 0.60 \\
\hline 3 & G003 & $\begin{array}{l}\text { IDLING } \\
\text { mesin buruk }\end{array}$ & K001 - Busi & 0.40 \\
\hline 4 & G004 & $\begin{array}{l}\text { Akselerasi } \\
\text { Buruk }\end{array}$ & K001 - Busi & 0.40 \\
\hline 5 & G005 & $\begin{array}{ll}\text { Mesin } & \text { Susah } \\
\text { Hidup } & \\
\end{array}$ & K001 - Busi & 0.30 \\
\hline 6 & G006 & Mesin Mogok & $\begin{array}{l}\text { K002-Pompa } \\
\text { Bahan Bakar }\end{array}$ & 0.70 \\
\hline 7 & G007 & $\begin{array}{l}\text { Mesin } \\
\text { Tersendat } \\
\text { sendat }\end{array}$ & $\begin{array}{l}\text { K002-Pompa } \\
\text { Bahan Bakar }\end{array}$ & 0.60 \\
\hline 8 & G008 & $\begin{array}{l}\text { Tarikan } \\
\text { Mesin Lemah }\end{array}$ & $\begin{array}{l}\text { K002-Pompa } \\
\text { Bahan Bakar }\end{array}$ & 0.60 \\
\hline 9 & G009 & $\begin{array}{ll}\text { Mesin Susah } \\
\text { Hidup }\end{array}$ & $\begin{array}{l}\text { K002-Pompa } \\
\text { Bahan Bakar }\end{array}$ & 0.60 \\
\hline
\end{tabular}




\begin{tabular}{|c|l|l|l|l|}
\hline 10 & G010 & $\begin{array}{l}\text { Temperatur } \\
\text { Mesin Tidak } \\
\text { Normal Air }\end{array}$ & $\begin{array}{l}\text { K003-Radiator } \\
\text { Bocor }\end{array}$ & 0.60 \\
\hline 11 & G011 & $\begin{array}{l}\text { Uap } \\
\text { Menyembur } \\
\text { Keluar Ke } \\
\text { Radiator }\end{array}$ & $\begin{array}{l}\text { Bocor } \\
\text { Badiator }\end{array}$ & 0.40 \\
\hline 12 & G012 & $\begin{array}{l}\text { Oli } \\
\text { Bercampur } \\
\text { dengan Air }\end{array}$ & $\begin{array}{l}\text { K003-Radiator } \\
\text { Bocor }\end{array}$ & 0.60 \\
\hline 13 & G013 & $\begin{array}{l}\text { Suara Mesin } \\
\text { Knocking }\end{array}$ & $\begin{array}{l}\text { K003-Radiator } \\
\text { Bocor }\end{array}$ & 0.40 \\
\hline 14 & G014 & $\begin{array}{l}\text { Mesin } \\
\text { Tersendat } \\
\text { Sendat }\end{array}$ & $\begin{array}{l}\text { K003-Radiator } \\
\text { Bocor }\end{array}$ & 0.50 \\
\hline 15 & G015 & $\begin{array}{l}\text { Oli Mesin } \\
\text { Berkurang }\end{array}$ & $\begin{array}{l}\text { K004- Ring } \\
\text { Piston Longgar }\end{array}$ & 0.50 \\
\hline 16 & G016 & $\begin{array}{l}\text { Mesin } \\
\text { Mengeluarkan } \\
\text { Asap }\end{array}$ & $\begin{array}{l}\text { K004- Ring } \\
\text { Piston Longgar }\end{array}$ & 0.50 \\
\hline 17 & G017 & $\begin{array}{l}\text { Lampu } \\
\text { Indikator Oli } \\
\text { Hidup Terus }\end{array}$ & $\begin{array}{l}\text { K004- Ring } \\
\text { Piston Longgar }\end{array}$ & 0.50 \\
\hline 18 & G018 & $\begin{array}{l}\text { Mesin Tidak } \\
\text { Dapat } \\
\text { Berputar }\end{array}$ & $\begin{array}{l}\text { K004- Ring } \\
\text { Piston Longgar }\end{array}$ & 0.50 \\
\hline 19 & G019 & $\begin{array}{l}\text { Suara Mesin } \\
\text { Kasar }\end{array}$ & $\begin{array}{l}\text { K004- Ring } \\
\text { Piston Longgar }\end{array}$ & 0.50 \\
\hline 20 & G020 & $\begin{array}{l}\text { Tarikan } \\
\text { Mesin Lemah }\end{array}$ & $\begin{array}{l}\text { K005- Knalpot } \\
\text { Tersumbat }\end{array}$ & 0.70 \\
\hline
\end{tabular}

Dempster-Shafer adalah suatu teori matematika yang bertujuan untuk membuktikan berdasarkan belief function and plausible reasoning (fungsi kepercayaan dan pemikiran yang masuk akal), yang digunakan untuk mengkombinasikan potongan informasi yang terpisah (bukti) untuk mengkalkulasikan kemungkinan dari suatu peristiwa (Dahria, Silalahi, \& Ramadhan, 2013). Pada Contoh dibawah ini, akan di cari persentase kemungkinan dari gangguan gangguan kerusakan dengan menggunakan perhitungan pada table dibawah ini:

Tabel 4. Contoh Gejala Kerusakan Busi (K001)

\begin{tabular}{|c|c|c|c|}
\hline No & Kode & Gejala & Bobot \\
\hline 1 & G001 & Bahan Bakar Boros & 0.50 \\
\hline 2 & G002 & $\begin{array}{c}\text { Mesin Tersendat } \\
\text { sendat }\end{array}$ & 0.60 \\
\hline
\end{tabular}

Maka untuk menghitung nilai Dempster Shafer (DS) gangguan kerusakan mobil yang dipilih dengan menggunakan nilai believe yang telah ditentukan pada setiap gejala.

$$
\mathrm{PI}(\Theta)=1-\text { Bel }
$$

Dimana nilai bel (believe) merupakan nilai bobot yang diinput oleh pakar, maka untuk mencari nilai dari kedua gejala diatas, terlebih dahulu dicari nilai dari $\Theta$, seperti yang dibawah ini.

Gejala 1 : Bahan Bakar Boros (G001)

Maka : GP001(bel) $=0.5$

$\mathrm{GP} 001(\Theta)=1-0,5$

$$
=0.5
$$

Gejala 2 : Mesin Tersendat sendat (G002)

Maka : GP18 (bel) $=0.6$

$\mathrm{GP} 18(\Theta)=1-0,6$

$=0,4$

Tabel 5. Ilustrasi keyakinan dari dua gejala

\begin{tabular}{|l|l|l|}
\hline & $\begin{array}{l}M 2\{\mathrm{~K} 001\} \\
0.6\end{array}$ & $M 2\{\Theta\} 0.4$ \\
\hline $\begin{array}{l}M 1 \\
\{\mathrm{~K} 001\} \\
0.5\end{array}$ & $\{\mathrm{~K} 001\} 0.30$ & $\{\mathrm{~K} 001\} 0.20$ \\
\hline $\begin{array}{l}M 1\{\Theta\} \\
0.5\end{array}$ & $\{\mathrm{~K} 001\} 0.30$ & $\{\Theta\} 0.20$ \\
\hline
\end{tabular}

Selanjutnya untuk menghitung tingkat keyakinan (m) combine dengan rumus, maka :

$m_{3}(Z)=\frac{\sum_{X \cap Y=Z} m_{1}(X) \cdot m_{2}(Y)}{1-\sum_{X \cap Y=\phi} m_{1}(X) \cdot m_{2}(Y)}$

Dimana:

$\mathrm{m} 3(\mathrm{Z})=$ mass function dari evidence $(\mathrm{Z})$

$\mathrm{m} 1(\mathrm{X})=$ mass function dari evidence $(\mathrm{X})$

$\mathrm{m} 2(\mathrm{Y})=$ mass function dari evidence $(\mathrm{Y})$

$\mathrm{Zm} 1(\mathrm{X}) \cdot \mathrm{m} 2(\mathrm{Y})=$ ada hasil irisan dari $\mathrm{m} 1$ dan $\mathrm{m} 2$

$\varnothing \mathrm{Zm} 1(\mathrm{X}) \cdot \mathrm{m} 2(\mathrm{Y})=$ tidak ada hasil irisan (irisan $\operatorname{kosong}(\varnothing)$

Maka:

$$
\begin{aligned}
M_{3}\{K 001\} & \\
= & \frac{(0.6 \times 0.5)+(0.4 \times 0.5)+(0.6 \times 0.5)}{1-0} \\
& =\frac{0.3+0.2+0.3}{1} \\
& =0,8
\end{aligned}
$$

Nilai keyakinan yang paling kuat terhadap kerusakan busi (K001) yaitu sebesar 0,80 (80\%) di dapat dari 2 gejala yaitu G001 dan G002.

Pada penelitian ini perancangan sistem dengan menggunakan UML (Unifield Modelling Languange). Dengan menggunakan UML perancangan dilakukkan untuk menguraikan relasi antara pengguna dengan aplikasi. Adapun UML yang digunakan adalah Use Case Diagram 
dan Activity Diagram untuk menjelaskan kerja dari sebuah aplikasi artificial intelligance yang sedehana.

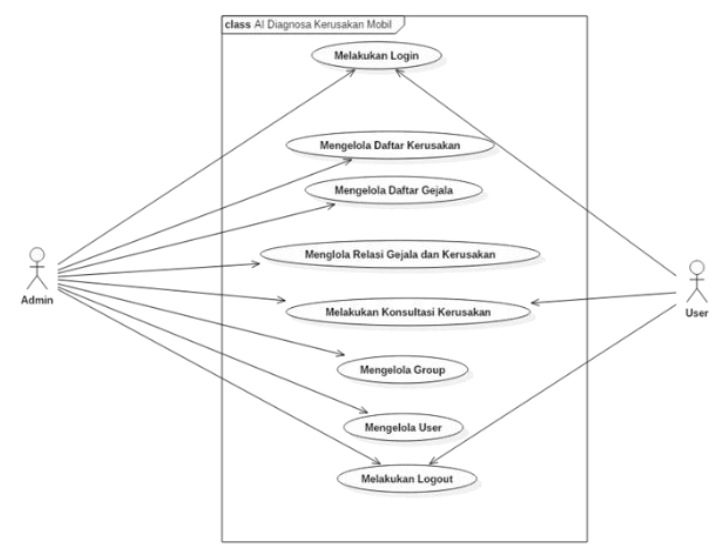

Gambar 3. Use case Diagram AI Diagnosa Kerusakan Mobil

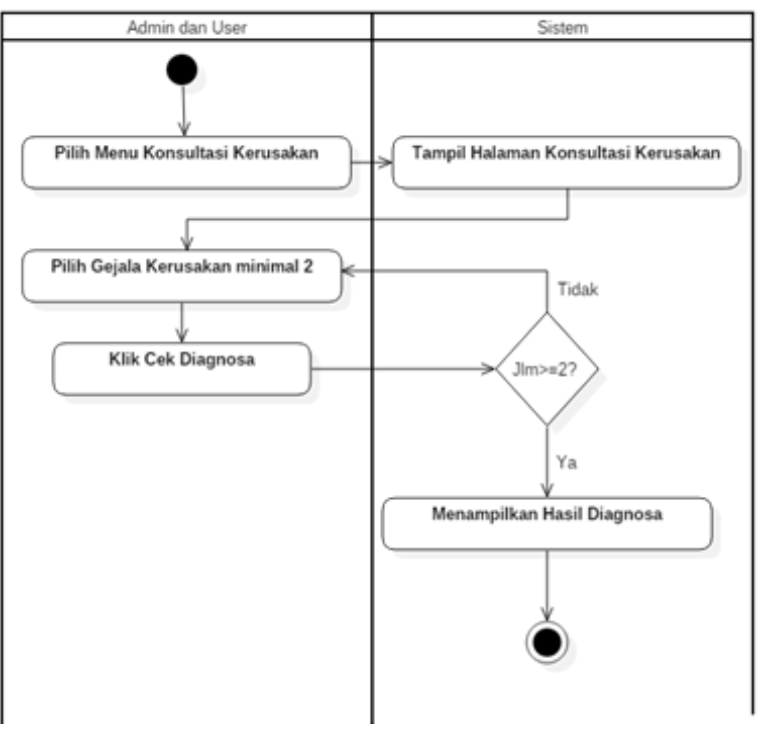

Gambar 4. Activity Digram Konsultasi Kerusakan

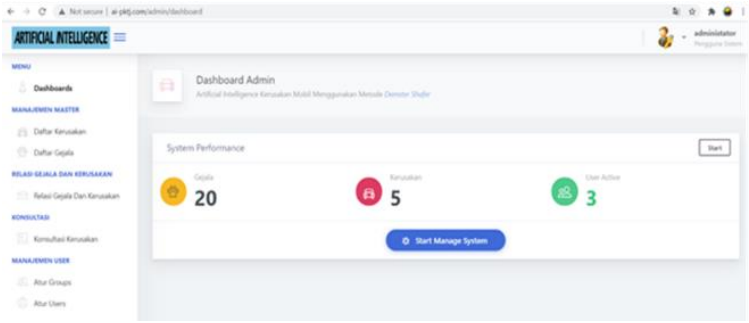

Gambar 5. Tampilan Halaman Admin
Pada gambar 5 merupakan tampilan halaman admin dari aplikasi diagnosa kerusakan mobil berbasis codeigniter, pada halaman ini admin bisa mengelola data gejala, kerusakan, relasi maupun data user.

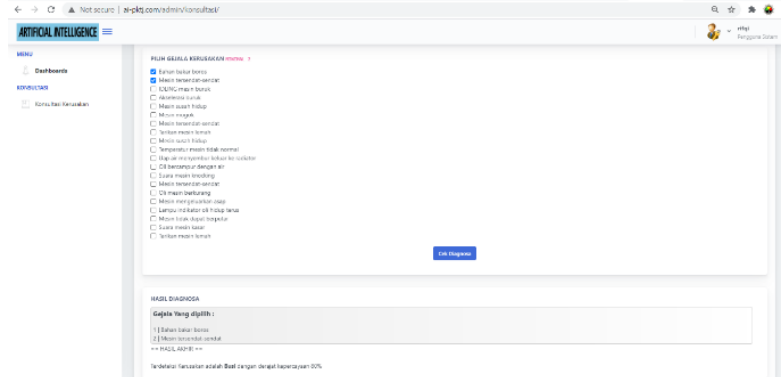

Gambar 6. Tampilan Halaman konsultasi

Pada gambar 6 merupakan tampilan halaman diagnosa dari aplikasi diagnosa kerusakan mobil berbasis codeigniter, pada halaman ini bisa memilih gejala kerusakan mobil 2.

Pengetesan program aplikasi dengan cara menjalankan aplikasi Pengujian ini bertujuan untuk mengetahui kelancaran dari fungsi tiap tiap komponen yang sudah dirancang dan sudah melalui tahap pengkodingan, memastikan semua komponen berfungsi dengan baik, aman dan lancar tanpa terkendala. Pengetesan ini juga untuk mengetahui integrasi setiap screen aplikasi serta untuk mengetahui integrasi block/modul logika pada aplikasi sesuai dengan kebutuhan yang dapat berintegrasi antara screen awal dengan screen akhir. Seperti pada Tabel 4.4 dibawah ini :

Tabel 6. Black Box Testing

\begin{tabular}{|l|l|l|c|}
\hline No & \multicolumn{1}{|c|}{ Pengujian "ai- } & \multicolumn{1}{|c|}{$\begin{array}{l}\text { Hasil Yang } \\
\text { Diharapkan }\end{array}$} & Hasil \\
\hline 1 & $\begin{array}{l}\text { Ketik url pada } \\
\text { pktj.com kalaman Login } \\
\text { browser untuk ke } \\
\text { halaman login }\end{array}$ & Valid \\
\hline 2 & $\begin{array}{l}\text { Input User dan } \\
\text { Password Pada Form } \\
\text { Login }\end{array}$ & $\begin{array}{l}\text { Masuk Aplikasi dan } \\
\text { Tampil Menu } \\
\text { Utama Admin/User }\end{array}$ & Valid \\
\hline 3 & $\begin{array}{l}\text { Klik Menu Daftar } \\
\text { Kerusakan }\end{array}$ & $\begin{array}{l}\text { Tampil Halaman / } \\
\text { Tabel Daftar } \\
\text { Kerusakan }\end{array}$ & Valid \\
\hline 4 & $\begin{array}{l}\text { Klik Menu Daftar } \\
\text { Gejala }\end{array}$ & $\begin{array}{l}\text { Tampil Halaman / } \\
\text { Tabel Daftar gejala }\end{array}$ & Valid \\
\hline 5 & $\begin{array}{l}\text { Klik Menu Relasi } \\
\text { Gejala } \\
\text { Kerusakan }\end{array}$ & $\begin{array}{l}\text { Tampil Halaman / } \\
\text { Tabel Daftar Relasi }\end{array}$ & Valid \\
\hline 6 & $\begin{array}{l}\text { Klik Menu Atur } \\
\text { Group }\end{array}$ & $\begin{array}{l}\text { Tampil Halaman / } \\
\text { Tabel Atur Group }\end{array}$ & Valid \\
\hline
\end{tabular}




\begin{tabular}{|l|l|l|r|}
\hline 7 & Klik Menu Atur User & $\begin{array}{l}\text { Tampil Halaman / } \\
\text { Tabel Atur User }\end{array}$ & Valid \\
\hline 8 & Klik Menu Delete & Data Terhapus & Valid \\
\hline 9 & Klik Menu Tambah & $\begin{array}{l}\text { Data Bertambah } \\
\text { dan Tersimpan }\end{array}$ & Valid \\
\hline 10 & Klik Menu Logout & $\begin{array}{l}\text { Keluar Dari } \\
\text { Aplikasi }\end{array}$ & Valid \\
\hline
\end{tabular}

\section{Kesimpulan}

Dari uraian yang telah disebutkan pada bab-bab yang sebelumnya, maka penulis mengambil kesimpulan sebagai berikut:

1. Aplikasi Artificial Intelligence Diagnosa Kerusakan Mobil Dengan Algoritma Dempster Shafer menggunakan bahasa pemrograman Codeigniter, dengan rancangan desain menggunakan UML dan Database dengan MySQL

2. Aplikasi Artificial Intelligence Diagnosa Kerusakan Mobil Dengan Algoritma Dempster Shafer Berbasis Codeigneter dapat membantu pengguna mobil/sopir untuk mendeteksi kerusakan awal pada mobil yang dipakai ataupun bisa sebagai media pembelajaran pada taruna PKTJ Tegal.

\section{Daftar Pustaka}

[1] Keng Siau and Qing Cao, 2001:26, Journal of Database Management, USA.

[2] Kusumadewi, Sri. 2003. Artificial Intelligence (Teknik dan Aplikasinya). Graha Ilmu. Yogyakarta.

[3] Kusumadewi, Sri. 2003. Artificial Intelligence (Teknik dan Aplikasinya). Graha Ilmu. Yogyakarta.
[4] L. Whitten, Jeffrey, \& D. Bentley, Lonnie .(2007). System Analysis \& Design Methods Seventh Edition. New York, USA : McGraw-Hill.

[5] Muhammad Dahria, Rosindah Silalahi, Mukhlis Ramadhan, 2013, "Sistem Pakar Metode Damster Shafer Untuk Menentukan Jenis Gangguan Perkembangan Pada Anak", Jurnal SAINTIKOM Vol. 12, No. 1, Januari 2013.

[6] Pressman, Roger, S. 2012. Rekayasa Perangkat Lunak.Pendekatan Praktisi. Edisi 7. Yogyakarta : Andi

[7] Rikhiana, Esthi Dyah dan Abdul Fadlil. 2013. Implementasi sistem pakar untuk mendiagnosa penyakit dalam pada manusia menggunakan metode dempster shafer. Jurnal Serjana Teknik Informatika Volume 1 nomor 1 eISSN : 2338-5197.

[8] Rizky Soetam, "Konsep Dasar RekayasaPerangkat Lunak", Jakarta: Prestasi Pustaka, 2011.

[9] Setright, LJK (2004). Drive On !: Sejarah Sosial Mobil Bermotor . Buku Granta. ISBN 1-86207-698-7 .

[10] Syahputra, S. \& dkk (2018). Sistem Pakar Deteksi dan Penanganan Kerusakan Pada Mesin Mobil dengan Metode Backward Chaining. Jurnal Teknik dan Informatika.

[11] Yusman, H. \& dkk (2017). Sistem Pakar Deteksi Kerusakan Dini Pada Mesin Mobil Toyota Dengan Metode Certainty Factor (CF) Berbasis Android. Jurnal rekursif. 